\title{
Role of gastric secretion in iron absorption
}

\author{
A. JACOBS AND P. M. MILES \\ From the Department of Pathology, Welsh National School of Medicine, Cardiff
}

\begin{abstract}
The availability of inorganic iron for absorption in the small intestine is largely dependent on its physical and chemical state when it reaches the point of entry into the epithelial cells of the jejunum. This state is influenced by intraluminal factors both in the stomach and the upper intestine. Iron absorption can be increased in achlorhydric subjects by the administration of hydrochloric acid (Jacobs, Bothwell, and Charlton, 1964) and in anaemic patients iron absorption is correlated with the amount of intrinsic acid secretion (Jacobs, Rhodes, Peters, Campbell, and Eakins, 1966). Ferric ions normally undergo polymerization followed by precipitation when acid solutions are brought to neutrality and ferrous ions in similar conditions tend to be oxidized to ferric forms. Acid limits the polymerization of iron in solution and prevents protein binding (Jacobs, 1967) so that at a low $p \mathrm{H}$ it is in a reactive state and potentially available for absorption. Beutler, Fairbanks, and Fahey (1963) found that normal gastric juice contains substances that stabilize iron and prevent it from being precipitated at raised $p \mathrm{H}$. When the $p \mathrm{H}$ of an inorganic iron solution is raised eventual precipitation can only be prevented if soluble complexes are formed with other substances. The present study confirms that normal gastric juice contains substances which combine with iron in this way at a low $p \mathrm{H}$ and maintain it in a soluble form at neutral $p \mathrm{H}$. This reaction is responsible for the availability of iron in a suitable state for absorption when it reaches the small intestine.
\end{abstract}

\section{METHODS}

Fresh solutions of iron salts with an approximate concentration of $1,000 \mu \mathrm{g}$ per $100 \mathrm{ml}$ were made up in $0.15 \mathrm{M}$ barbitone-acetate buffer (Michaelis) at $p \mathrm{H} 2$ 2. Of this solution $50 \mathrm{ml}$ was diluted with $50 \mathrm{ml}$ of $p \mathrm{H} 2$ buffer in a small beaker to give a final iron concentration of about $500 \mu \mathrm{g}$ per $100 \mathrm{ml}$. The amount of precipitation occurring at progressive stages in the slow neutralization of the iron solution was measured. The solution was mixed vigorously with a magnetic stirrer throughout the procedure and $p \mathrm{H}$ measurements were recorded by an EIL Vibron $p \mathrm{H}$ meter with an electrode remaining in the mixture. $p \mathrm{H}$ was increased by the slow addition of a
12.5 M NaOH solution through a finely drawn out capillary tube. About an hour was taken to reach neutrality. At short stages through the procedure a sample was removed from the reacting mixture after time had been given for full equilibration of $p \mathrm{H}$. All samples were left to stand for 18 hours at room temperature before centrifugation and the iron remaining in the supernatant fluid was estimated by the tripyridyl triazine method of Young and Hicks (1965). The same procedure was carried out after the initial dilution of the iron solution with normally acid gastric juice instead of buffer. The gastric juice used for this purpose was free of blood and bile and had been aspirated during a histamine infusion, filtered through gauze and immediately neutralized. A portion was acidified again immediately before each experiment. Other substances tested in the same way for their effect on iron solubility were extracts of hog stomach (Armour) and intrinsic factor concentrate (Lederle), a $5 \%$ solution of pepsin powder BPC, and $0 \cdot 1 \mathrm{M}$ solutions of histidine and glutamic acid in $p \mathrm{H} 2$ buffer. Gel filtration was carried out using Sephadex G-25 and G-200 with 0.15 M Michaelis buffer as the eluant.

\section{RESULTS}

The stability in solution of three ferrous saltssulphate, gluconate, and glycine sulphate-and of three ferric salts-chloride, sulphate (as ferric ammonium sulphate), and citrate-was measured and the results are shown in Figure 1a. Solubility of the iron as the $p \mathrm{H}$ approaches neutrality is related to the formation of soluble complexes with the associated anions. This does not occur to any extent with sulphate or chloride ions but in the presence of citrate or gluconate a stable complex is formed which is soluble at neutrality. The somewhat greater solubility of ferrous iron compared to ferric iron at $p \mathrm{H} 4$ to 6 is probably related to the marked tendency of ferric iron to undergo polymerization and precipitation above $p \mathrm{H} \mathrm{3}$. When solutions of ferrous or ferric salts which would normally be completely precipitated at $p \mathrm{H} 7$ are mixed with gastric juice before neutralization they form complexes with ligands in the gastric juice. These complexes are soluble at neutrality (Fig. 1b). When this procedure is carried out with gastric juice which has been incubated at $p \mathrm{H} 1.5$ to 2 for eight hours at $37^{\circ} \mathrm{C}$ the same effect is obtained. Since the complexing agents 


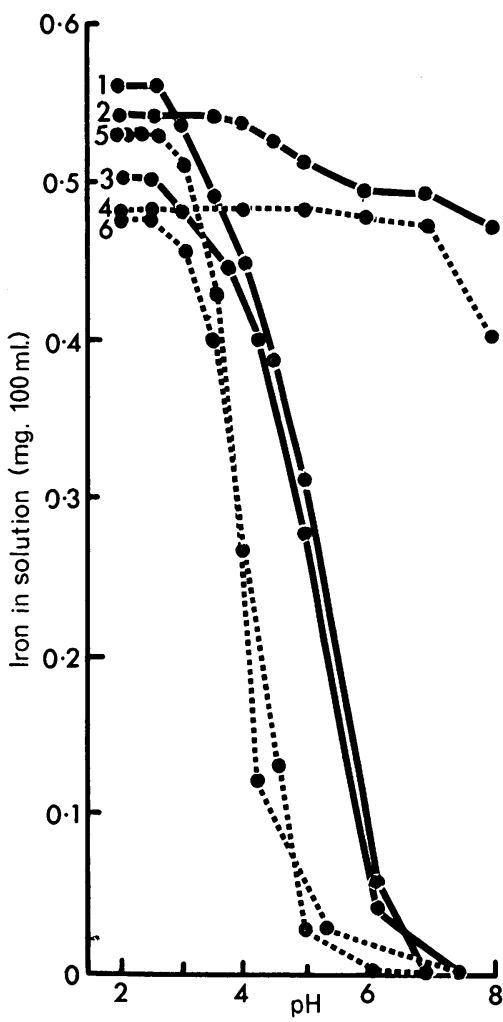

FIG. 1a.

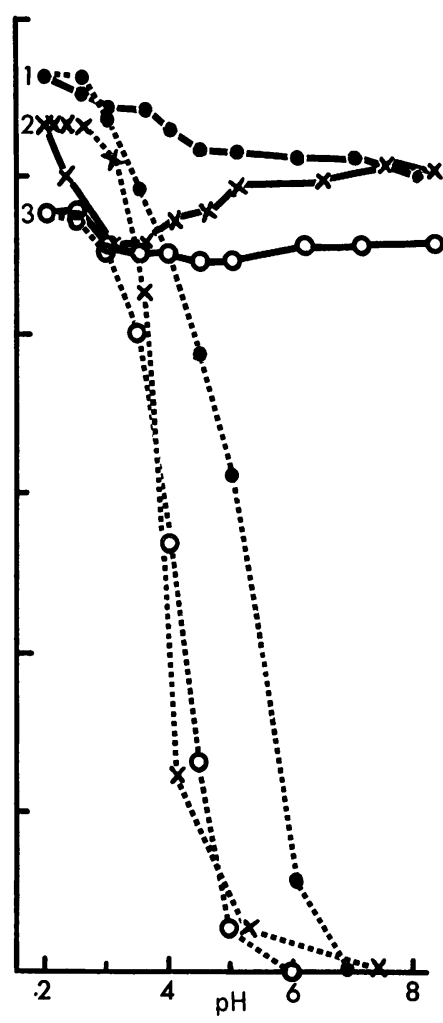

FIG. 1 b.

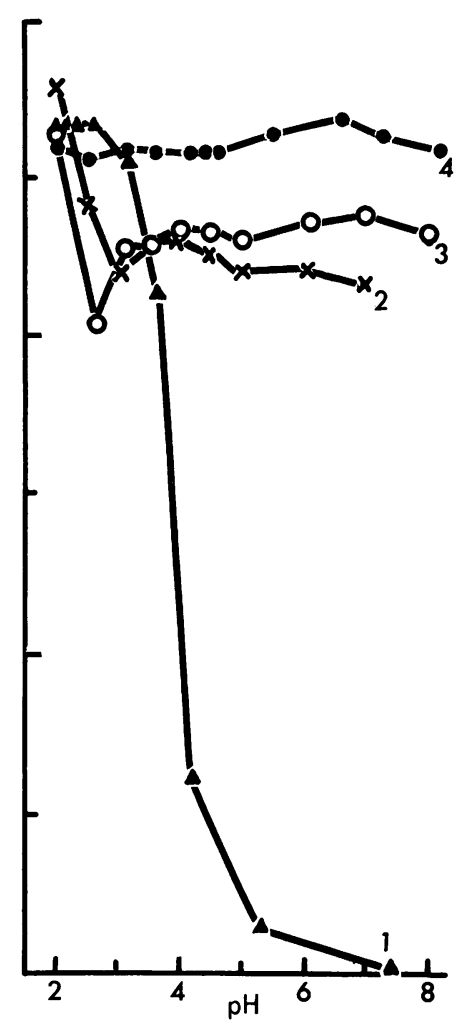

FIG. 1c.

FIG. 1. (a) The solubility of six iron compounds in the $\mathrm{pH}$ range 2 to 8 . Ferric salts ......... Ferrous salts 1 Ferrous sulphate, 2 ferrous gluconate, 3 ferrous glycine sulphate, 4 ferric citrate, 5 ferric ammonium sulphate, 6 ferric chloride; (b) the solubility of three iron compounds alone and together with gastric juice. Without gastric juice ......... With gastric juice —. 1 Ferrous sulphate, 2 ferric ammonium sulphate, 3 ferric chloride; (c) the solubility of ferric iron together with 1 Michaelis buffer, 2 hog stomach extract, 3 intrinsic factor concentrate, $45 \%$ pepsin solution.

in gastric juice are resistant to peptic digestion they are unlikely to be protein in nature. Similar complexing agents are found in hog stomach extract and intrinsic factor concentrate (Fig. 1c). The BPC preparation of pepsin shows similar activity but it is not clear whether this is due to pepsin itself or to an impurity. Histidine in a $0 \cdot 1 \mathrm{M}$ solution produced an iron complex soluble at $p \mathrm{H} 7$ but glutamic acid at the same concentration was ineffective.

Gel filtration of the supernatant solutions of the ferric ammonium sulphate-gastric juice mixtures was carried out with a Sephadex G-25 column having a void volume of $60 \mathrm{ml}$. In the $p \mathrm{H}$ range 2 to 4 iron is eluted at $120 \mathrm{ml}$ corresponding to a complex of small molecular weight. At $p \mathrm{H} 5$ to 7 it is eluted in the void volume. Gel filtration at $p \mathrm{H} 6$ with Sephadex G-200 also results in the iron appearing in the void volume suggesting that it is bound in a complex with a molecular weight in excess of 200,000 . This same high molecular weight complex is found at $p \mathrm{H}$
6 when peptic digested gastric juice is used and it seems probable that the iron-containing fraction includes either a mucopolysaccharide or a polymer derived from a smaller complex.

\section{DISCUSSION}

Ferric and ferrous ions are able to form complexes with many substances. In the gastric juice this occurs at low $p \mathrm{H}$ where reactive, small molecular weight ions are present which can react with suitable ligands. If soluble complexes are not formed at low $p \mathrm{H}$ then neutralization results in polymerization and precipitation of the iron. Hydrochloric acid in the stomach, therefore, provides the conditions in which iron can be made soluble by complex formation. Solubility of iron is a necessary condition for absorption though it does not follow that all such complexes are necessarily available for absorption. A hypothetical scheme showing the effect 


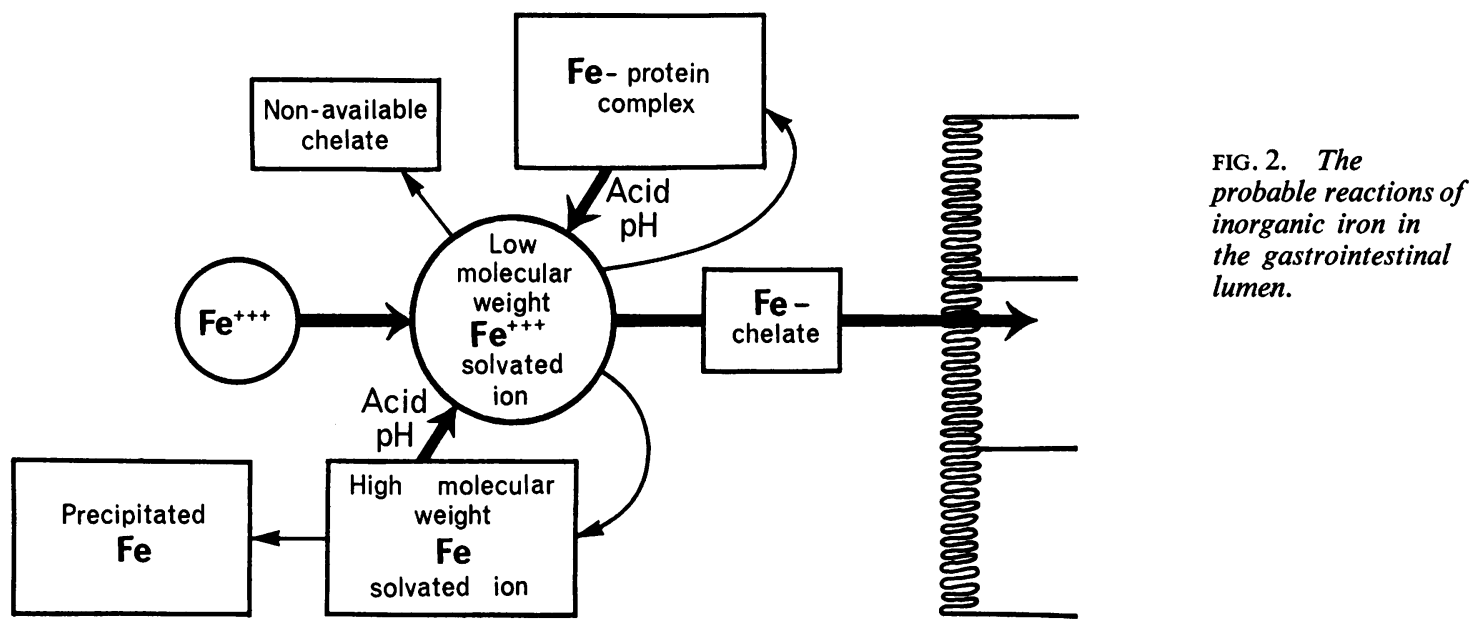

of acid and complexing agents in the gut lumen is shown in Figure 2. The effect of an acid $p \mathrm{H}$ in limiting polymerization of ferric ions and preventing protein binding has been previously demonstrated (Jacobs, 1967). Iron in the small intestine may enter the epithelial cell either in ionic form at low $p \mathrm{H}$ or as a low molecular weight complex formed in the gut lumen. Iron bound to a large molecule is unlikely to enter the epithelial cell in that form and might exchange with an intracellular ligand at the cell membrane in a manner analogous to the uptake of intrinsic factor-bound vitamin $\mathbf{B}_{12}$.

The necessity of an intact stomach for optimal iron absorption has been shown by several studies on postgastrectomy patients (Turnberg, 1967) and animals (Whitehead and Bannerman, 1964). Murray and Stein (1967) have demonstrated that in gastrectomized animals the defect is in secretion rather than the anatomical abnormality caused by the operation. In iron-deficiency anaemia the small intestinal epithelium responds by increasing absorption of inorganic iron, but in those cases where gastric secretion is impaired iron absorption is limited (Jacobs et al, 1966). Normal gastric juice provides both the acid $p \mathrm{H}$ and the ligands necessary for the formation of soluble iron complexes, and in its absence the availability of iron is likely to be reduced at the site of absorption. The breakdown products formed by the digestion of protein and carbohydrate foods provide additional ligands for forming iron complexes. Kroe, Kinney, Kaufman, and Klavins (1963) showed that glutamic acid and histidine both facilitated iron absorption in rats and thought that this might be due to the formation of chelates. Only histidine was found to form a soluble complex under the conditions used in the present study.
It has been suggested that the gastric secretions play a more active role in regulating iron absorption but we have found no evidence for this. Koepke and Stewart (1964) found that anaemic dogs secreted a gastric substance capable of increasing iron absorption in normal dogs but it was not possible to demonstrate this in human subjects (Jacobs, Rhodes, and Eakins, 1967). Davis, Luke, and Deller (1966), using a radioactive iron solubility test (Davis, 1965). demonstrated iron binding by gastric juice and considered this to be a necessary inhibitory mechanism preventing excessive absorption in normal subjects. This concept is not in accord with the findings in postgastrectomy subjects or those with gastric atrophy and we have found no inhibition of iron absorption by gastric juice in patients with complete achlorhydria (Jacobs and Owen, 1969). The present findings show that normal gastric juices enable inorganic iron to remain in a soluble form so that it is available for absorption by the small intestine. This important function is likely to be affected by any factors influencing gastric secretion.

\section{SUMMARY}

Inorganic iron is able to form complexes with normal gastric juice constituents at a low $p \mathrm{H}$. These complexes remain soluble when the $p \mathrm{H}$ is raised to neutrality and enable the iron to be available in a suitable state for absorption in the small intestine. The presence of normal gastric juice is an important factor in facilitating iron absorption.

We should like to thank Dr R. P. Houghton for his valuable advice. Professor $\mathrm{H}$. Scarborough and the Board of Governors of the United Cardiff Hospitals have given us generous support. 


\section{REFERENCES}

Beutler, E., Fairbanks, V. F., and Fahey, J. L. (1963). In Clinical Disorders of Iron Metabolism. Grune and Stratton, New York.

Davis, P. S. (1965). Formation of metal chelates in biological systems. Methods of investigation. Proc. Aust. Ass. clin. Biochem., 1, 190-192.

—, Luke, C. G., and Deller, D. J. (1966). Reduction of gastric ironbinding protein in haemochromatosis. Lancet, 2, 1431-1433.

Jacobs, A. (1967). Effect of gastric juice and $p H$ on inorganic iron in solution. Nature (Lond.), 216, 707-708.

—, and Owen, G. M. (1969). The effect of gastric juice on iron absorption in patients with gastric atrophy. Gut, in the press.

__, Rhodes, J., and Eakins, J. (1967). Gastric factors influencing iron absorption in anaemic patients. Scand. J. Haemat., 4, 105-110.

- - —, Peters, D. K., Campbell, H., and Eakins, J. D. (1966).
Gastric acidity and iron absorption, Brit. J. Haemat., 12, 728736.

Jacobs, P., Bothwell, T., and Charlton, R. W. (1964). Role of hydrochloric acid in iron absorption. J. appl. Physiol., 19, 187-188.

Koepke, J. A., and Stewart, W. B. (1964). Role of gastric secretion in iron absorption. Proc. Soc. exp. Biol. (N.Y.), 115, 927-929.

Kroe, D., Kinney, T. D., Kaufman, N., and Klavins, J. V. (1963). The influence of amino acids on iron absorption. Blood, 21, 546-552.

Murray, M. J., and Stein, N. (1967). The integrity of the stomach as a requirement for maximal iron absorption. J. Lab. clin. Med., 70, 673-677.

Turnberg, L. A. (1967). Iron absorption tests. In Post-gastrectomy Nutrition, pp. 65-71. Edited by D. M. Krikler Lloyd-Luke, London.

Whitebead, J. S. W., and Bannerman, R. M. (1964). Absorption of iron by gastrectomized rats. Gut, $5,38-44$.

Young, D. S., and Hicks, J. M. (1965). Method for the automatic determination of serum iron. J. clin. Path., 18, 98-102.

\section{The February 1969 Issue}

\section{THE FEBRUARY 1969 ISSUE CONTAINS THE FOLLOWING PAPERS}

\section{Signposts}

Cholera-a clue to 'functional diarrhoea'? G. E. SLADEN and A. M. DAWSON

The coeliac axis and its branches in splenomegaly and liver disease LAURENCE BLENDIS, LOUIS KREEL, and ROGER WILLIAMS

Effect of gastrectomy on billiary dynamics A. P. WYATT

Carcinoma of bile ducts in husband and wife c. F. MCCARTHY and H. J. ESPINER

Deposition of amyloid in the gastrointestinal tract T. GILAT, M. REVACH, and E. SOHAR

Permeability characteristics of the cholera-infected small intestine A. H. G. LOVE

Malignancy and adult coeliac disease w. T. COOKE, H. THOMPSON, and J. ALEXANDER WILLIAMS

Three-dimensional structure of the rat small intestinal mucosa related to mucosal dynamics.

Part I: Mucosal structure and dynamics in the rat after the administration of methotrexate.

Part II: Mucosal structure and dynamics in the lactating rat.

Part III: Mucosal structure and dynamics in the rat infested with the nematode Nippostrongylus brasiliensis C. A. LOEHRY and B. CREAMER
Experimental study of devascularization of the colon ADRIAN MARSTON, R. W. MARCUSON, M. CHAPMAN, and J. F. ARTHUR

Early diagnosis of ischaemic colitis F. T. DE DOMBAL, D. M. FLETCHER, and R. S. HARRIS

Inhibition of gastric secretion in man by intestinal fat infusion COLIN W. O. WINDSOR, ROY COCKEL, and MARTIN J. R. LEE

Influence of hyperaldosteronism upon gastric secretion R. M. BADDELEY, JANICE EVANS, and J. A. GRIFFIN

Choledochoduodenal fistula complicating chronic duodenal ulcer in Nigerians E. A. LEWIS and S. P. BOHRER

Geographical distribution of stomach cancer in Czechoslovakia O. GREGOR, R. TOMAN, F. PRUŠOVÁ, V. DRNKOVÁ, and J. PASTOROVÁ

Present position of the electrical stimulation test $H$. BURGE, T. B. L. ROBERTS, R. D. STEDEFORD, and M. J. LANCASTER.

New method of measuring forces in the anal canal C. D. COLLINS, B. H. BROWN, G. E. WHITTAKER, and H. L. DUTHIE

\section{Techniques}

Mounting and storage of gastrocamera films J. R. KIRKPATRICK and R. J. MARSHALL

Comment

Notes and activities

Copies are still available and may be obtained from the PUBLISHING MANAGER, BRITISH MEDICAL ASSOCIATION, TAVISTOCK SQUARE, W.C.1, price 17s. 6D. 